\title{
Establishment of a Tongue Squamous Cell Carcinoma Cell Line from Indian Gutka Chewer
}

\author{
Tejas T. Patil, ${ }^{1}$ Pradnya K. Kowtal, ${ }^{2}$ Abhijeet Nikam, ${ }^{1}$ Madan S. Barkume, ${ }^{1}$ Asawari Patil, ${ }^{3}$ \\ Shubhada V. Kane, ${ }^{3}$ Aarti S. Juvekar, ${ }^{1}$ Manoj B. Mahimkar, ${ }^{4}$ and Jyoti J. Kayal ${ }^{1}$ \\ ${ }^{1}$ Anti-Cancer Drug Screening Facility, Advanced Centre for Treatment, Research and Education in Cancer, \\ Tata Memorial Centre, Kharghar, Navi Mumbai 410 208, India \\ ${ }^{2}$ Sarin Lab, Advanced Centre for Treatment, Research and Education in Cancer, Tata Memorial Centre, Kharghar, \\ Navi Mumbai 410 208, India \\ ${ }^{3}$ Department of Pathology, Tata Memorial Hospital, Tata Memorial Centre, Mumbai 400 012, India \\ ${ }^{4}$ Mahimkar Lab, Cancer Research Institute, Advanced Centre for Treatment, Research and Education in Cancer, Tata Memorial Centre, \\ Kharghar, Navi Mumbai 410 208, India
}

Correspondence should be addressed to Manoj B. Mahimkar; mmahimkar@actrec.gov.in and Jyoti J. Kayal; jyotikayal@yahoo.com Received 7 November 2013; Accepted 17 April 2014; Published 15 May 2014

Academic Editor: Yih-Shou Hsieh

Copyright ( $\odot 2014$ Tejas T. Patil et al. This is an open access article distributed under the Creative Commons Attribution License, which permits unrestricted use, distribution, and reproduction in any medium, provided the original work is properly cited.

CD cell line has been established from a poorly differentiated squamous cell carcinoma of tongue. This is a first ever cell line established from an Indian gutka chewer. Cell line was characterized for morphology, ultrastructure, doubling time, expression of epithelial markers, DNA content, karyotyping, STR markers, p53 mutations, HPV status, and tumorigenicity in SCID mice with all-trans-retinoic acid and cisplatin. The epithelial phenotype of the cell line was confirmed with surface markers and ultrastructure. The cell line is hyperploid with chromosomal alterations like gain of chromosomes 8q and 11q. CD cell line shows a unique pattern on STR genotyping and carries a missense mutation R273C in TP53. It does not show genomic integration of HPV. The cells are nontumorigenic to SCID mice and show growth inhibition upon treatment with cisplatin, and all-trans-retinoic acid. This cell line may be useful as an in vitro tool to understand the molecular changes associated with oral cancers.

\section{Introduction}

Cancer of oral cavity is the third most common cancer in India (http://globocan.iarc.fr/Pages/online.aspx). The important risk factors identified so far are tobacco use and alcohol consumption, which seem to have a synergistic effect. Statistics for head and neck squamous cell cancers (HNSCCs) throughout the world show these cancers to be prevalent in areas where consumption of tobacco and alcohol is high [1]. The process of oral carcinogenesis is multifactorial with interplay of various environmental factors. Though treatment modalities have shown an advancement, the survival rates of oral cancer patients have not improved markedly over the past few decades [2].

Tumor derived cell lines form a useful resource as model systems with reflections of the original tumors [3]. Therefore, development of cell lines from tumor tissues will aid in understanding the events associated with development of cancer. Moreover, cell lines are required to study the effects of various known and novel drug formulations and help in studying future treatment strategies. In spite of these advantages, there are very few cell lines developed from Indian oral cancer patients [4-6].

We have established an oral cancer cell line CD from a young gutka chewer. Gutka is a dry mixture of areca nut, catechu, and slaked lime with tobacco. Due to its easy availability and low cost, it has become popular chewing substitute in young Indian tobacco habitués. Use of gutka has been strongly implicated in increased incidence of oral submucous fibrosis, a precancerous lesion, which has a high rate of malignant transformation, even after a short period of use [7-9]. In this report, we describe the establishment and characterization of oral cancer cell line derived from gutka user. We have characterized the in vitro growth and genetic characteristics of this cell line for authentication. This cell line may serve as useful tool to unravel the regulatory pathways in 
oral carcinogenesis and may help in better understanding of oral cancer biology.

\section{Materials and Methods}

2.1. Tumor Specimen Collection and Establishment of Cell Line. Surgically resected fresh tongue tumor sample was obtained from a 34-year-old male gutka chewer through the Bio-Repository, Advanced Centre for Treatment Research and Education in Cancer (ACTREC), Navi Mumbai. The tumor tissue was collected aseptically in plain Dulbecco's Modified Eagle's Medium (DMEM, Invitrogen, USA) containing double strength antibiotic mixture of gentamycin $50 \mu \mathrm{g} / \mathrm{mL}$, streptomycin $125 \mu \mathrm{g} / \mathrm{mL}$, and antifungal antibiotic forcan $150 \mu \mathrm{g} / \mathrm{mL}$. The tumor tissue was washed thoroughly in PBS with double strength antibiotic mixture and cut into smaller pieces which were incubated in trypsin $(0.025 \%)$ for $30 \mathrm{~min}$ at $37^{\circ} \mathrm{C}$. The tumor tissue was freed of blood vessels and adhering tissue. Explant cultures were set up in DMEM containing 10\% fetal bovine serum (Invitrogen, USA) and double strength antibiotic mixture. The medium was supplemented with epidermal growth factor (EGF) $5 \mathrm{ng} / \mathrm{mL}$, insulin $5 \mu \mathrm{g} / \mathrm{mL}$, hydrocortisone $0.4 \mu \mathrm{g} / \mathrm{mL}$, sodium selenite $5 \mathrm{ng} / \mathrm{mL}$, and transferrin $10 \mu \mathrm{g} / \mathrm{mL}$. Medium was changed after $48 \mathrm{~h}$ and the epithelial pool of cells was enriched by differential trypsinization and subsequent removal of fibroblasts. The cell line was established by subculturing further and enriching the epithelial cells.

2.2. Light and Electron Microscopy. Using inverted phase contrast microscope, cell cultures were photographed at 20x magnification. The cells were grown as monolayer in petri dishes and processed for ultrastructure analysis as reported earlier [6]. Briefly, the cells were washed with $3 \%$ glutaraldehyde in $0.1 \mathrm{M}$ sodium cacodylate buffer and were scraped with rubber policeman. After $1 \mathrm{~h}$ of fixation, the cells were washed with the same buffer and postfixed with $1 \%$ osmium tetraoxide. The cells were dehydrated through a series of graded alcohol, embedded in araldite, and polymerized at $60^{\circ} \mathrm{C}$ for $45 \mathrm{~h}$. Ultrathin sections of $60-70 \mathrm{~nm}$ thickness were cut, contrasted with uranyl acetate and lead citrate. The sections were examined under transmission electron microscope (Tecnai G2) at $80 \mathrm{kV}$.

2.3. Growth Characteristics. The cells were collected and seeded at a concentration of $1 \times 10^{4}$ cells per well in 6-well plates. Cell count of three random wells was taken every day up to 5 days using trypan blue method. The doubling time was calculated according to the formula $T_{d}=T \times$ $\log 2 / \log \left(N / N_{0}\right)$, where $T_{d}$ is the doubling time; $T$ is the time interval; $N$ is the final cell number; and $N_{0}$ is the initial cell number [10].

2.4. Determination of Tumorigenicity. The in vivo tumorigenicity of the cell line was evaluated by injecting $1 \times 10^{7}$ cells subcutaneously into dorsal flank of the SCID mice. Mice were observed for development of tumors for four months.
2.5. Soft Agar Colony Formation Assay. Anchorage-independent growth of the cell line was monitored by soft agar assay. Different number of cells $\left(1 \times 10^{3}, 5 \times 10^{3}\right.$, and $1 \times$ $\left.10^{4}\right)$ were suspended in $0.3 \%(\mathrm{w} / \mathrm{v})$ agar layered over a $0.6 \%$ (w/v) base agar. Agar was supplemented with DMEM, 10\% FBS, and growth supplements. The plates were incubated at $37^{\circ} \mathrm{C}$ in $\mathrm{CO}_{2}$ incubator for a month and observed for colony formation.

2.6. Chromosome Analysis and DNA Flow Cytometry. Karyotyping of the cell line was carried out by culturing $5 \times$ $10^{5}$ cells in $25 \mathrm{~cm}^{2}$ flasks. After $24 \mathrm{~h}$, the cells were arrested in metaphases by incubating the cultures with colchicine at $1 \mu \mathrm{g} / \mathrm{mL}$ for $2-3 \mathrm{~h}$ at $37^{\circ} \mathrm{C}$. The cultures were harvested, incubated in hypotonic $(0.075 \mathrm{M}) \mathrm{KCl}$ for $30 \mathrm{~min}$ at $37^{\circ} \mathrm{C}$, fixed in fresh, cold methanol acetic acid fixative, and stored at $4^{\circ} \mathrm{C}$. The slides were prepared by dropping the fixed cells on clean glass slides and G-banded using standard protocol. A minimum of 50 metaphase spreads was counted for model number and at least five G-banded karyotypes were made for the cell line. The DNA content of the cell line was measured by flow cytometry over a 3 -day period by seeding $5 \times 10^{5}$ cells per plate in triplicate for 3 time points of $24 \mathrm{~h}, 48 \mathrm{~h}$, and $72 \mathrm{~h}$ as reported earlier [5]. Ten thousand events were acquired on Becton-Dickinson FACS SCAN and the data was analyzed using Modfit software. Human peripheral blood lymphocytes were used as control.

2.7. Fluorescence In Situ Hybridization (FISH). The results of karyotyping were validated by interphase FISH (I-FISH) using 8q24.3, 1lq13 locus specific probes; centromere-specific probe for the respective chromosome served as a hybridization control for all FISH experiments. A dual color procedure was followed as previously described [11, 12].

2.8. Immunocytochemical Studies. The cells grown on coverslips were fixed either in ice cold methanol followed by $0.3 \%$ TritonX 100 for probing with anticytokeratin antibodies AE1 (Invitrogen), CK8, and CK 18 (Sigma) or in 1\% paraformaldehyde for antiepithelial membrane antigen (Invitrogen), antiEGFR (Invitrogen), and antibasic fibroblast growth factor antibodies (Abcam). Goat anti-mouse IgG labeled with FITC was used as secondary antibodies (Sigma). The nuclear staining was carried out by ethidium bromide or Hoechst 33258 staining.

2.9. TP53 Mutation Analysis. DNA was isolated from CD cells by using commercially available DNA purification column (Qiagen Catalogue Number 51104) following the manufacturer's instructions. The primer sequences to amplify exons 1-11 of TP53 gene were synthesized and used as described [13] with minor modifications.

2.10. DNA Profiling. Genomic DNA extracted as above was used for DNA profiling. DNA was amplified by PCR using short tandem repeats (STRs) markers. Cell line was genotyped using 3100 Avant Genetic Analyzer (Applied Biosystems, USA) for 8 autosomal STRs (CSF1PO, D5S818, D7S820, 


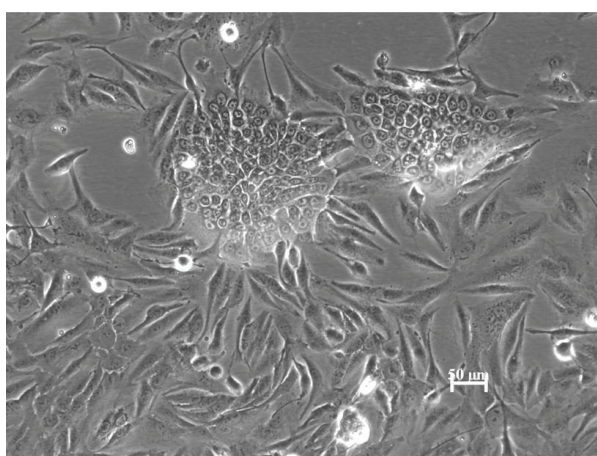

(a)

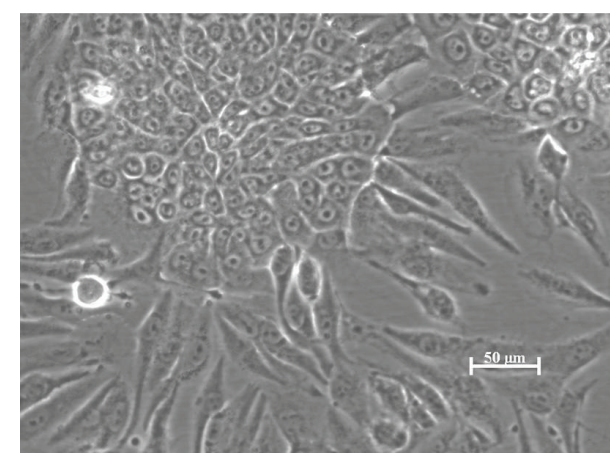

(b)

FIGURE 1: Epithelial colonies and fibroblast-like cells in primary culture at (a) $(\mathrm{DIC} \times 200)$ and (b) (DIC $\times 400)$.

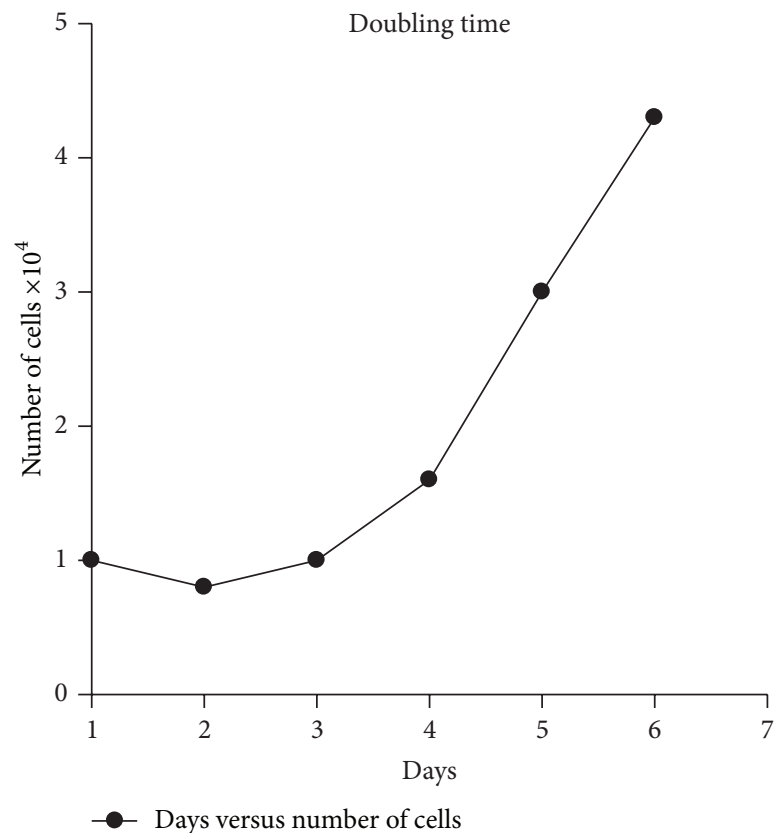

Figure 2: Growth curve of CD cell line.

D13S317, D16S539, THO1, TPOX, and vWA) and the gender determining amelogenin marker.

2.11. Cytotoxicity Assay. The cells at a density of $2 \times 10^{3}$ per well were seeded in 96-well plates and allowed to grow for $24 \mathrm{~h}$ and thereafter the cells in quadruplets were treated with all-trans-retinoic acid (ATRA) (Sigma) and cisplatin (Cipla) for different time points from 1 to 4 days. ATRA was used at various concentrations ranging from $0.0005 \mu \mathrm{M}$ to $0.5 \mu \mathrm{M}$ while cisplatin was used at $0.0005 \mu \mathrm{g}$ to $10 \mu \mathrm{g} / \mathrm{mL}$. The effect on growth was observed using the MTT assay [14].

\section{Results}

3.1. Establishment of Cell Line. The cell line CD (Cancer Research Institute-developed) was established from a poorly differentiated squamous cell carcinoma excised from tongue. Initially, within 8-10 days of explant cultures, the culture showed two different populations of cells with epithelial and fibroblastic morphology. Small patches of epithelial cells (Figures 1(a) and 1(b)) were enriched by removing fibroblasts using the method of differential trypsinization. The resulting cultures were pooled and expanded further. Over subsequent passages, fibroblastic cell population was removed selectively by differential trypsinization and the epithelial population was enriched. The cell line exhibited a doubling time of about $31 \pm 1 \mathrm{~h}$ (Figure 2).

3.2. Analysis of Epithelial Markers. The epithelial nature of the culture was ascertained by immunostaining with antibodies against epithelial membrane antigen and EGFR (Figure 3(a)). The removal of fibroblasts was confirmed by negative staining with fibroblast surface protein specific antibody (Figure 3(b)). The ultrastructure analysis further supported the epithelial nature of the cell line. The transmission electron micrographs of cell sections demonstrated irregular 


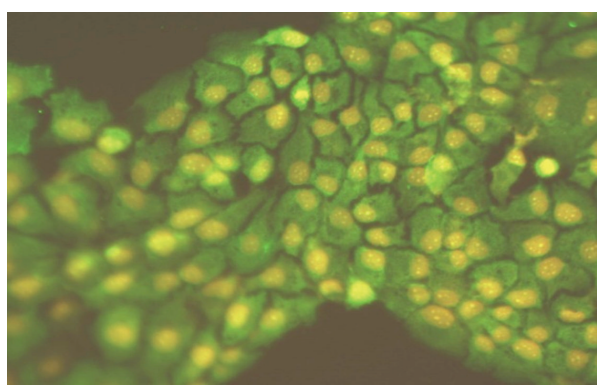

(a)

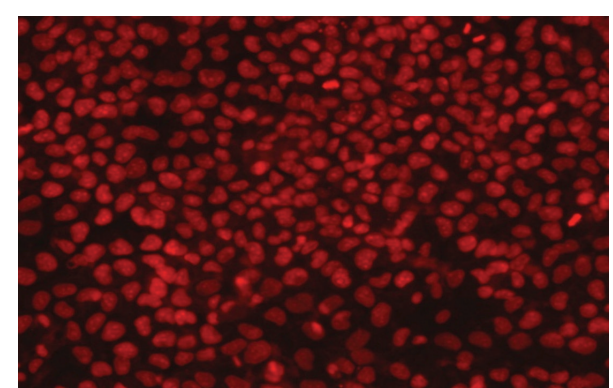

(b)

FIGURE 3: Immunofluorescent staining of CD cells for the presence of (a) epithelial membrane antigen and (b) absence of fibroblast specific antigen.

nuclear envelope. It also showed presence of bundles of intermediate filament like structures in cytoplasm and microvilli on the cell surface (Figures 4(a) and 4(b)), indicative of the epithelial origin of the cells. Confocal imaging of the enriched epithelial population devoid of fibroblasts showed staining for the epithelial markers with pan cytokeratin antibody (Figure 5(a)), cytokeratin 8 (Figure 5(b)), and epidermal growth factor receptor (Figure 5(c)). This confirmed that the cell line is derived from epithelial cells.

3.3. In Vivo Tumorigenicity and Soft Agar Assay. An in vivo tumorigenicity test showed that $\mathrm{CD}$ cells were nontumorigenic in SCID mice when injected subcutaneously. Soft agar assay showed that CD cells formed colonies in soft agar after about a month showing anchorage-independent growth.

3.4. Chromosome, Flow Cytometry, and FISH Analysis. Chromosome analysis of $\mathrm{CD}$ cell line showed human male karyotype. The chromosome number ranged from 68 to 74 and displayed aneuploidy. Most of the metaphases showed one marker chromosome (Figure 6). Flow cytometric analysis revealed the hyperploid nature of the cell line (Figure 7), thus confirming the results of karyotyping. Further, the locus specific FISH analysis validated the results of karyotype (Figure 8).

3.5. HPV Infection and TP53 Analysis. High risk HPV infection has been implicated in OSCCs and many studies have examined the relationship between HPV infections and head and neck SCCs. CD cells were analyzed for the presence of HPV DNA by PCR amplification and the cells did not show genomic integration of HPV (Figure 9). Mutations in TP53 gene were detected in CD cell line. A well-documented 16base-pair homozygous deletion in TP53 gene was found in the cell line. This $16 \mathrm{bp}$ deletion ( $\mathrm{rs} 17878362$ ) has been reported as a polymorphism in the TP53 database of the International Agency of Research in Cancer (IARC). A known deleterious homozygous mutation R273C (CGT to TGT at codon 273 changing an arginine residue to a cysteine) was also detected in this cell line (Figure 10).

3.6. DNA Profiles. In order to authenticate the cell line, CD cells were genotyped for 8 STR markers and one gender
TABLE 1: Analysis of STR markers in the CD cell line.

\begin{tabular}{lc}
\hline Locus & Observed alleles \\
\hline CSF1PO & $9.3,12$ \\
D5S818 & 11,13 \\
D7S820 & 10 \\
D13S317 & 8,13 \\
D16S539 & 10,12 \\
THO1 & 7 \\
TPOX & 9,11 \\
vWA & $14,19.2$ \\
AMEL & $X, Y$ \\
\hline
\end{tabular}

determining marker (Table 1). STR profile confirmed that the cell line has a unique genotype.

3.7. Cytotoxicity Analysis. The effect of retinoic acid, a differentiation inducer, and cisplatin was studied for growth inhibition using the MTT assay. As seen in Figure 11(b), cisplatin showed a dose dependent growth inhibition of the cells as compared to control over a 4 -day period. At $10 \mu \mathrm{g} / \mathrm{mL}$ and $5 \mu \mathrm{g} / \mathrm{mL}$ concentrations, on day 4 , only 29 and $32 \%$ cells were surviving, respectively, as compared to $100 \%$ in controls (Figure 11(b)). However, retinoic acid showed a marginal growth inhibition, even at a concentration as high as $0.5 \mu \mathrm{M}$, of $81 \%$ and $71 \%$ surviving cells by days 3 and 4 , respectively (Figure 11(a)).

\section{Discussion}

Difficulties and low success rates have been well reported in establishing cell lines from oral tumor tissue [15-17]. Here, we describe the establishment and characterization of CD cell line from a poorly differentiated primary tongue tumor. There are very few reports regarding the development of cell lines from smokeless tobacco users from Asian countries including India $[4,5,18]$. It is interesting to note that the patient was a young tobacco habitue and this is the first cell line developed from an Indian gutka chewer. Cancers of head and neck arise as a result of accumulation of genetic changes. The most important etiological factor associated with the development of these cancers is use of tobacco for smoking or in various 


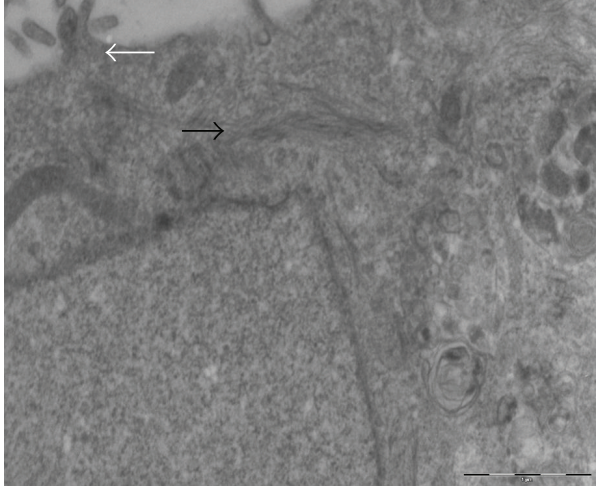

(a)

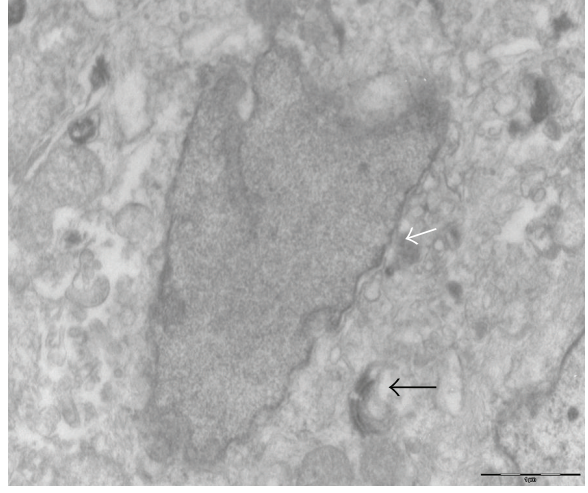

(b)

FIGURE 4: Transmission electron microscopy images of the CD cells exhibiting (a) cytoplasmic filaments (black arrow) and microvilli (white arrow) and (b) rough nuclear membrane (white arrow) and desmosomes (black arrow).

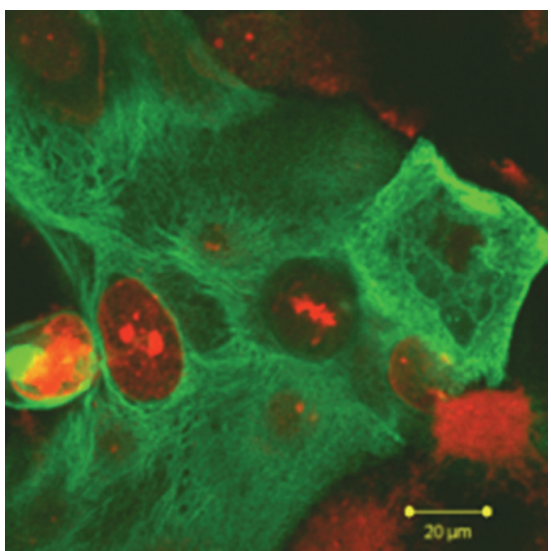

(a)

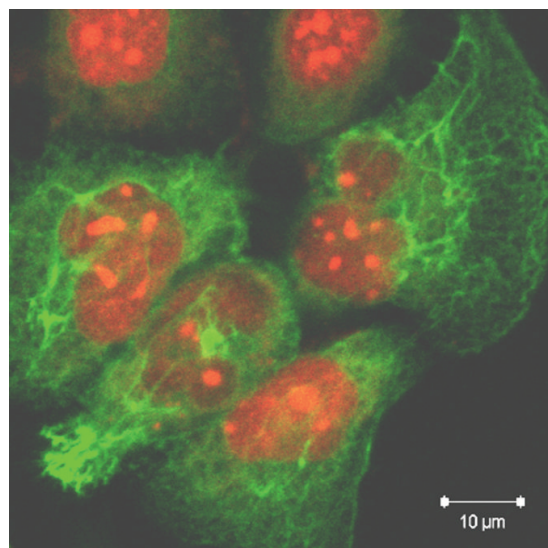

(b)

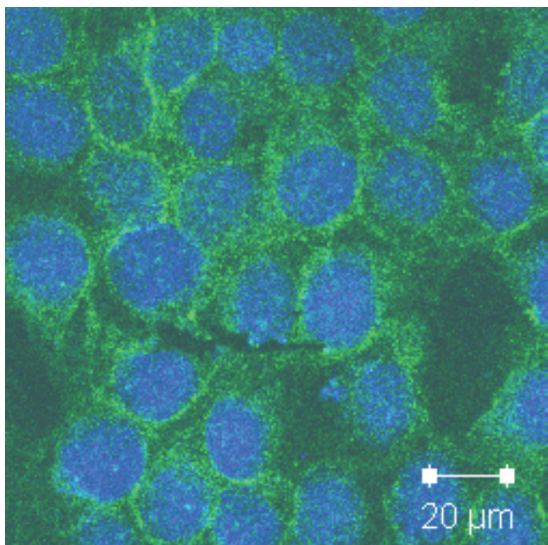

(c)

FIgURE 5: Expression of (a) pan cytokeratin, (b) cytokeratin 8, and (c) epidermal growth factor receptor on CD cells.

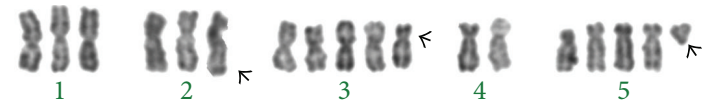

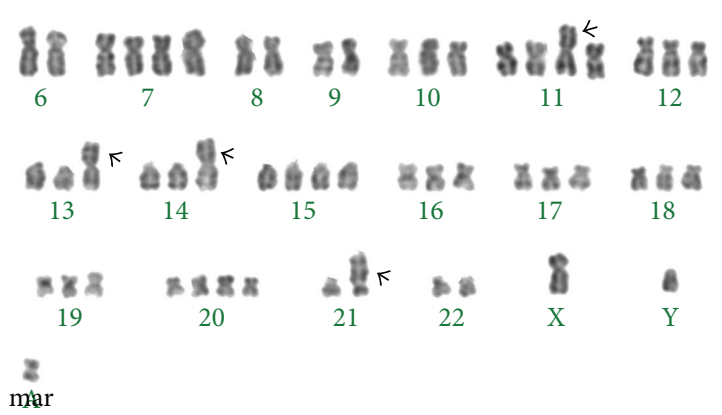

FIgURE 6: Karyotype of CD cells showing multiple chromosomal alterations.

smokeless forms $[1,19]$. White et al. have reported that the majority of tumors that yielded a cell line were from patients who were smokers while few cell lines developed from tumors of nonsmokers [3]. Smoking has stronger causative links than smokeless tobacco use which is directly related to the duration and dose $[1,20]$. However, tobacco use was not found to be significantly associated with the formation of cell line because accounting for exposure levels based on type of tobacco use is difficult [3]. Hence, the cell line developed from the tumor of a smokeless tobacco chewer may be a valuable research tool.

The cell line is epithelial in nature and shows expression of epithelial membrane antigen and EGFR. Negative staining by antifibroblast antibody negated the contamination of fibroblast cells. Further, the ultrathin sections of CD cells show presence of cytoplasmic filaments, microvilli, and desmosomes confirming their epithelial origin. The cells express cytokeratins which belong to class of intermediate filament proteins and are involved with regulation of cell proliferation, differentiation, and cell death. Cytokeratins are known to form an extensive network with desmosomes on plasma membranes of epithelial cells. Apart from staining positive to pan keratin antibodies, the cells are immunopositive to CK8 antibodies, confirming their epithelial nature. Downregulation of CK8 has been reported to decrease the tumorigenic potential, alterations in cell motility, and organization of 


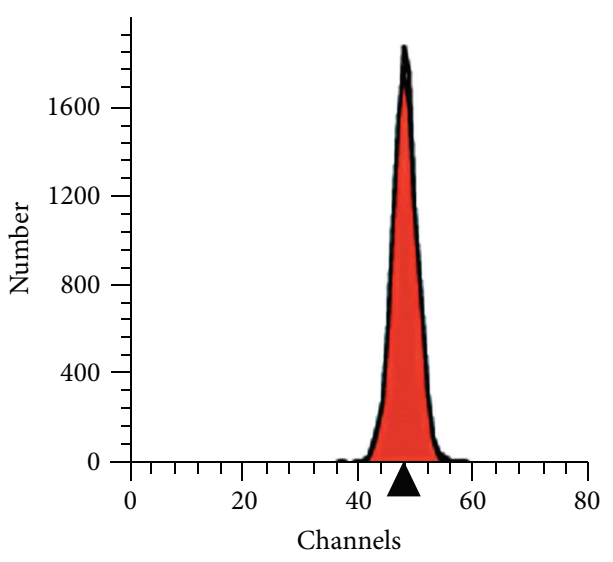

(a)

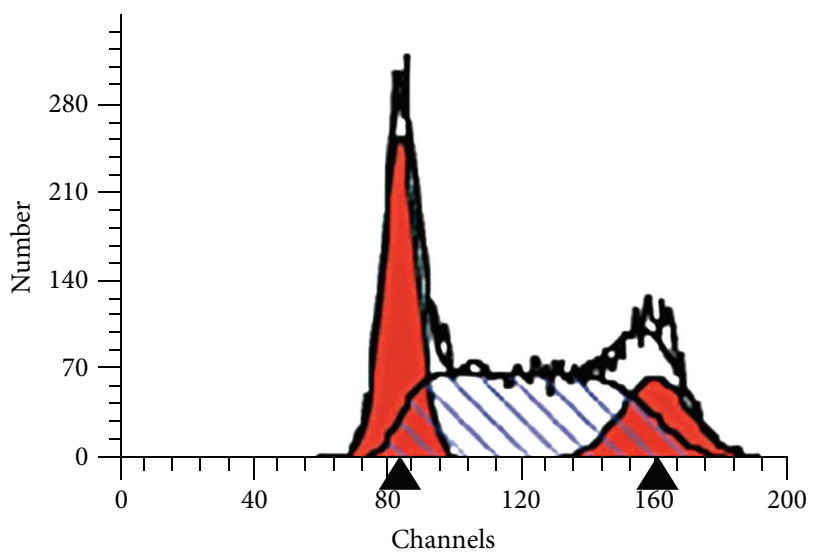

(b)

FIGURE 7: Flow cytometric analysis of the CD cell line. (a) Normal lymphocytes with diploid peak and (b) CD cells with hyperploidy.

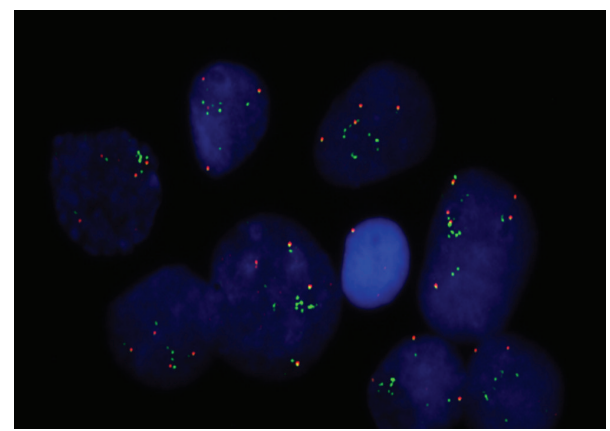

FIGURE 8: FISH analysis of CD cells with red signal indicating centromeres and green signal indicating 11q13 locus.
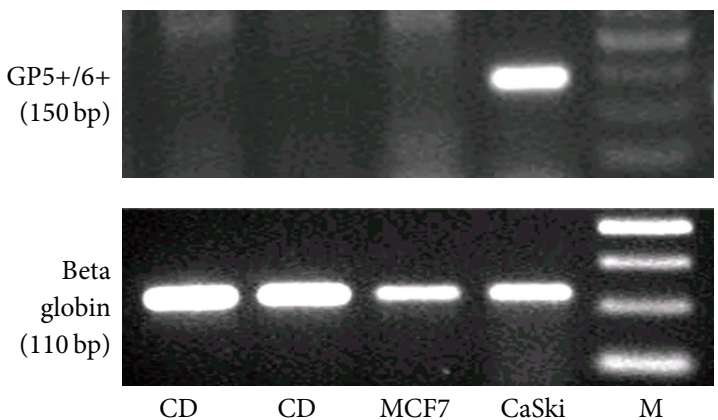

FIGURE 9: Screening of CD cells for HPV DNA. HPV 16 was not detected in CD cells. Controls used CaSki positive control for HPV 16 and MCF7 as negative control. M: 50 bp marker.

cytoskeleton in a tongue cancer cell line [21, 22]. Although CD cells show expression of CK8, they are nontumorigenic in SCID mice but formed colonies in semisolid agar, suggestive of transformed phenotype which is similar to the earlier reports $[4,17]$.

The cells are hyperploid in nature and show chromosomal alterations peculiar to HNSCC indicating chromosomal instability as reported earlier in oral cancer cell lines
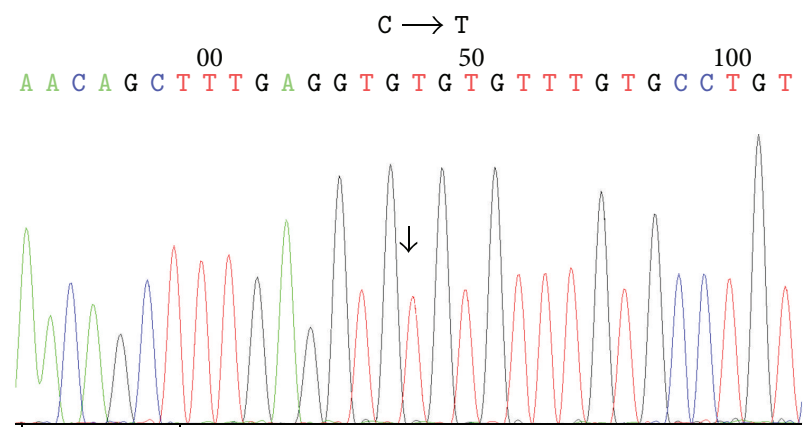

FIgURE 10: Chromatogram depicting a homozygous missense somatic mutation R273C in TP53 in CD cells.

$[23,24]$. In fact, correlation of gain/amplification of 11q13 band has been reported in about $45 \%$ of oral and head and neck squamous cell carcinomas [24]. FISH analysis also depicts the gain of 11q13 locus in our cell line which is consistent with the karyotype data.

Although the etiology of oral cancer is not very clear, there is substantial evidence that the disease development underlies the activation of protooncogenes and the inactivation of tumor suppressor genes. To understand the mechanism underlying the development of oral cancer, the status of HPV infection, protooncogene (EGFR), and tumor suppressor (TP53) was investigated. Human papillomavirus (HPV) infection is associated with a subset of head and neck squamous cell carcinoma (HNSCC). HPV-infected oropharyngeal tumors comprise a distinct molecular, clinical, and pathological disease entity with distinct genetic alterations and better prognosis when treated with radiation or chemoradiation [25-29]. At a molecular level, HPV-positive OPSCC is associated with increased expression of wild-type p53, reduced expression of the epidermal growth factor receptor (EGFR), and downregulation of cyclin D and pRb [2]. CD cell line derived from chronic tobacco gutka user does not show genomic integration of HPV which is in agreement with earlier reports of other cell lines [30, 31]. Further, it has also 


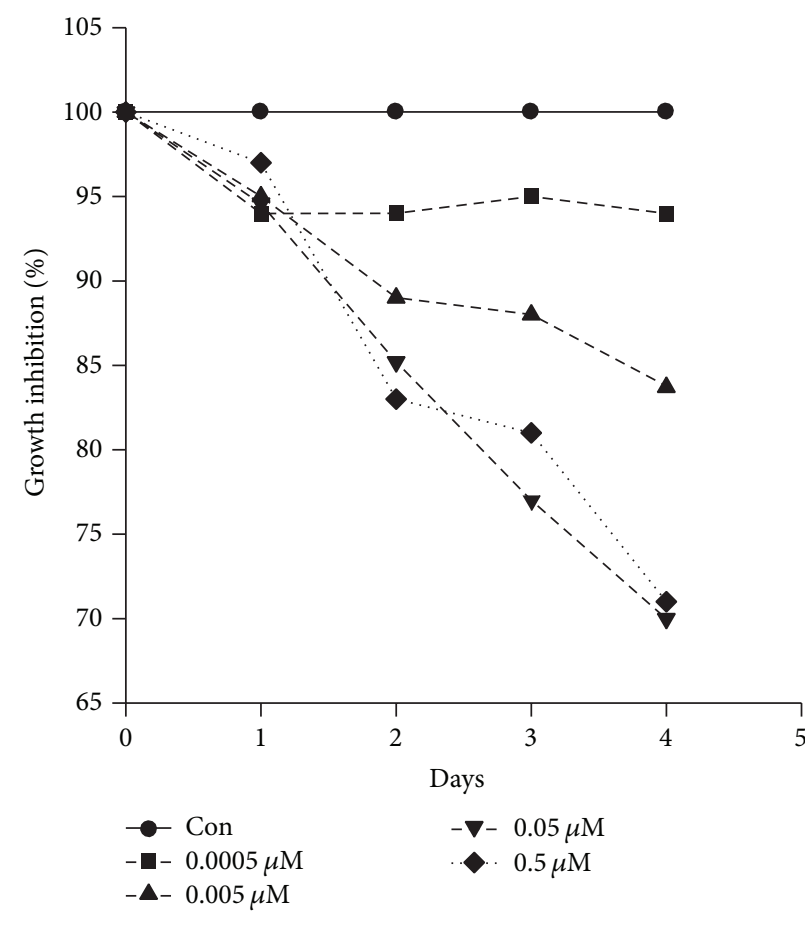

(a)

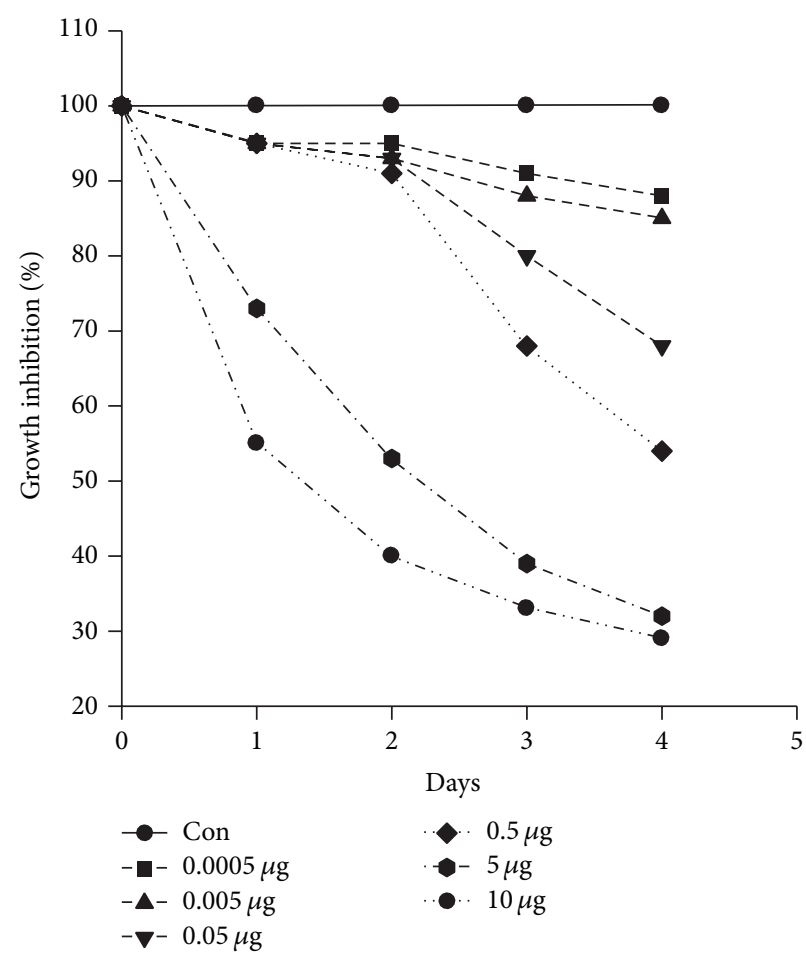

(b)

FIGURE 11: Effect of (a) retinoic acid and (b) cisplatin on CD cells using cell viability MTT assay.

been reported that HPV infections are detected in tumors with intact TP53 pathway [32]. However, absence of HPV infection in the cells suggests that HPV is not associated with the development of oral cancer in this particular individual, indicating that mutation in TP53 protein may have given growth advantage to this cell line. Therefore, we examined CD cell line for the mutation in the TP53 genes. Genetic characterization showed a 16-base-pair homozygous deletion and an amino acid change at codon 273 . The 16 bp deletion has been reported as a polymorphism in the TP53 IARC database (rs17878362) and the mutation at codon 273 has previously been reported in OSCC cell lines [33]. To understand the role of protooncogene, we examined the expression of EGFR in the cell line. EGFR is known to be overexpressed in several epithelial malignancies and also in HNSCCs [34]. Our results were also in accordance with the reports mentioned. It has been reported that a mutant P53 protein may transactivate the promoter of the gene expressing human EGFR, resulting in more aggressive growth of the cells [35].

Role of ATRA in the management of tobacco related oral cancers has been suggested earlier [4]. CD cells did not show any morphological changes upon treatment of ATRA although growth inhibition was observed at higher ATRA concentrations. Cisplatin based combinatorial chemotherapy is often used for the treatment of oral cancers although its use is limited due to acquired resistance [36]. However, CD cells are sensitive to the treatment of cisplatin. Thus, this cell line can be used as an in vitro model system to study tobacco induced oral cancers and the effect of various chemotherapeutic drugs used in treatment. The establishment of cell lines for research purposes is crucial but is biased towards more aggressive tumors, which are likely the result of interactions between multiple relevant exposures and consequent genetic alterations. Hence, it is critical that information about the tumor and the patient from which a cell line was derived is well documented especially when it is used for translational research [3].

In summary, this cell line developed from a gutka chewer provides an in vitro model system established from smokeless tobacco induced oral squamous carcinoma. The cell line with its hyperdiploid nature and drug sensitivity will be very useful for screening of anticancer drugs and new drug formulations.

\section{Conflict of Interests}

The authors declare that there is no conflict of interests regarding the publication of this paper.

\section{Acknowledgments}

The authors acknowledge the support of the facilities Tumour Tissue Repository, for providing tumor tissue, imaging facility for confocal, light, and fluorescence microscopy, and flow cytometry, and EM facility at ACTREC, Tata Memorial Centre, Kharghar, Navi Mumbai. The authors also thank Dr. Serena, National Institute for Research in Reproduction, Parel, Mumbai, and Mrs. Sharada Sawant, ACTREC, Tata Memorial Centre, Kharghar, Navi Mumbai, for help with 
electron microscopy. They also thank Dr. Sadhana Ghaisas for help in karyotyping.

\section{References}

[1] S. S. Hecht, "Tobacco carcinogens, their biomarkers and tobacco-induced cancer," Nature Reviews Cancer, vol. 3, no. 10, pp. 733-744, 2003.

[2] C. R. Leemans, B. J. M. Braakhuis, and R. H. Brakenhoff, "The molecular biology of head and neck cancer," Nature Reviews Cancer, vol. 11, no. 1, pp. 9-22, 2011.

[3] J. S. White, J. L. Weissfeld, C. C. R. Ragin et al., “The influence of clinical and demographic risk factors on the establishment of head and neck squamous cell carcinoma cell lines," Oral Oncology, vol. 43, no. 7, pp. 701-712, 2007.

[4] J. Kaur and R. Ralhan, "Establishment and characterization of a cell line from smokeless tobacco associated oral squamous cell carcinoma," Oral Oncology, vol. 39, no. 8, pp. 806-820, 2003.

[5] R. Mulherkar, A. P. Goud, A. S. Wagle et al., "Establishment of a human squamous cell carcinoma cell line of the upper aerodigestive tract," Cancer Letters, vol. 118, no. 1, pp. 115-121, 1997.

[6] R. J. Tatake, N. Rajaram, R. N. Damle, B. Balsara, A. N. Bhisey, and S. G. Gangal, "Establishment and characterization of four new squamous cell carcinoma cell lines derived from oral tumors," Journal of Cancer Research and Clinical Oncology, vol. 116, no. 2, pp. 179-186, 1990.

[7] D. S. Aruna, K. V. V. Prasad, G. R. Shavi, J. Ariga, G. Rajesh, and M. Krishna, "Retrospective study on risk habits among oral cancer patients in karnataka cancer therapy and research institute, hubli, India," Asian Pacific Journal of Cancer Prevention, vol. 12, no. 6, pp. 1561-1566, 2011.

[8] P. C. Gupta, "Mouth cancer in India: a new epidemic?" Journal of the Indian Medical Association, vol. 97, no. 9, pp. 370-373, 1999.

[9] U. Nair, H. Bartsch, and J. Nair, "Alert for an epidemic of oral cancer due to use of the betel quid substitutes gutkha and pan masala: a review of agents and causative mechanisms," Mutagenesis, vol. 19, no. 4, pp. 251-262, 2004.

[10] J. Wulong, L. Zhou, Z. Xiaojian, T. Jie, and G. Huilin, "Establishment of a highly metastatic tongue squamous cell carcinoma cell line from New Zealand White rabbit," Archives of Oral Biology, vol. 53, no. 11, pp. 1084-1090, 2008.

[11] S. Ambatipudi, M. Gerstung, R. Gowda et al., "Genomic profiling of advanced-stage oral cancers reveals chromosome $11 \mathrm{q}$ alterations as markers of poor clinical outcome," PLOS ONE, vol. 6, no. 2, Article ID e17250, 2011.

[12] S. Pathare, A. A. Schäffer, N. Beerenwinkel, and M. Mahimkar, "Construction of oncogenetic tree models reveals multiple pathways of oral cancer progression," International Journal of Cancer, vol. 124, no. 12, pp. 2864-2871, 2009.

[13] Y. Liu and W. F. Bodmer, "Analysis of P53 mutations and their expression in 56 colorectal cancer cell lines," Proceedings of the National Academy of Sciences of the United States of America, vol. 103, no. 4, pp. 976-981, 2006.

[14] T. Mosmann, "Rapid colorimetric assay for cellular growth and survival: application to proliferation and cytotoxicity assays," Journal of Immunological Methods, vol. 65, no. 1-2, pp. 55-63, 1983.

[15] E. J. Lee, J. Kim, S. A. Lee et al., "Characterization of newly established oral cancer cell lines derived from six squamous cell carcinoma and two mucoepidermoid carcinoma cells," Experimental and Molecular Medicine, vol. 37, no. 5, pp. 379390, 2005.
[16] G. E. Moore, S. B. Merrick, L. K. Woods, and N. M. Arabasz, "A human squamous cell carcinoma cell line," Cancer Research, vol. 35, no. 10, pp. 2684-2688, 1975.

[17] H. T. Rupniak, C. Rowlatt, and E. B. Lane, "Characteristics of four new human cell lines derived from squamous cell carcinomas of the head and neck," Journal of the National Cancer Institute, vol. 75, no. 4, pp. 621-635, 1985.

[18] S. Hamid, K. P. Lim, R. B. Zain et al., "Establishment and characterization of Asian oral cancer cell lines as in vitro models to study a disease prevalent in Asia," International Journal of Molecular Medicine, vol. 19, no. 3, pp. 453-460, 2007.

[19] K. D. Hunter, E. K. Parkinson, and P. R. Harrison, "Profiling early head and neck cancer," Nature Reviews Cancer, vol. 5, no. 2, pp. 127-135, 2005.

[20] M. L. Gillison, W. M. Koch, and K. V. Shah, "Human papillomavirus in head and neck squamous cell carcinoma: are some head and neck cancers a sexually transmitted disease?" Current Opinion in Oncology, vol. 11, no. 3, pp. 191-199, 1999.

[21] H. Alam, S. T. Kundu, S. N. Dalal, and M. M. Vaidya, "Loss of keratins 8 and 18 leads to alterations in $\alpha 6 \beta 4$-integrin-mediated signalling and decreased neoplastic progression in an oraltumour-derived cell line," Journal of Cell Science, vol. 124, no. 12, pp. 2096-2106, 2011.

[22] M. M. Vaidya, A. M. Borges, S. A. Pradhan, and A. N. Bhisey, "Cytokeratin expression in squamous cell carcinomas of the tongue and alveolar mucosa," European Journal of Cancer Part B: Oral Oncology, vol. 32, no. 5, pp. 333-336, 1996.

[23] C. L. Martin, S. C. Reshmi, T. Ried et al., "Chromosomal imbalances in oral squamous cell carcinoma: examination of 31 cell lines and review of the literature," Oral Oncology, vol. 44, no. 4, pp. 369-382, 2008.

[24] S. M. Gollin, "Chromosomal alterations in squamous cell carcinomas of the head and neck: window to the biology of disease," Head Neck, vol. 23, no. 3, pp. 238-253, 2001.

[25] M. L. Gillison, "Human papillomavirus-associated head and neck cancer is a distinct epidemiologic, clinical, and molecular entity," Seminars in Oncology, vol. 31, no. 6, pp. 744-754, 2004.

[26] J. P. Klussmann, J. J. Mooren, M. Lehnen et al., "Genetic signatures of HPV-related and unrelated oropharyngeal carcinoma and their prognostic implications," Clinical Cancer Research, vol. 15, no. 5, pp. 1779-1786, 2009.

[27] C. Fakhry, W. H. Westra, S. Li et al., "Improved survival of patients with human papillomavirus-positive head and neck squamous cell carcinoma in a prospective clinical trial," Journal of the National Cancer Institute, vol. 100, no. 4, pp. 261-269, 2008.

[28] D. Rischin, R. J. Young, R. Fisher et al., "Prognostic significance of p16INK4Aand human papillomavirus in patients with oropharyngeal cancer treated on TROG 02.02 phase III trial," Journal of Clinical Oncology, vol. 28, no. 27, pp. 4142-4148, 2010.

[29] K. K. Ang, J. Harris, R. Wheeler et al., "Human papillomavirus and survival of patients with oropharyngeal cancer," The New England Journal of Medicine, vol. 363, no. 1, pp. 24-35, 2010.

[30] P. K. Ha, S. I. Pai, W. H. Westra et al., "Real-time quantitative PCR demonstrates low prevalence of human papillomavirus type 16 in premalignant and malignant lesions of the oral cavity," Clinical Cancer Research, vol. 8, no. 5, pp. 1203-1209, 2002.

[31] J. P. Klussmann, S. J. Weissenborn, and U. Wieland, "Prevalence, distribution, and viral load of human papillomavirus 16 DNA in tonsillar carcinomas," Cancer, vol. 92, no. 11, pp. 2875-2884, 2001. 
[32] M. L. Gillison, W. M. Koch, R. B. Capone et al., "Evidence for a causal association between human papillomavirus and a subset of head and neck cancers," Journal of the National Cancer Institute, vol. 92, no. 9, pp. 709-720, 2000.

[33] L.-L. Hsieh, P.-F. Wang, I.-H. Chen et al., "Characteristics of mutations in the p53 gene in oral squamous cell carcinoma associated with betel quid chewing and cigarette smoking in Taiwanese," Carcinogenesis, vol. 22, no. 9, pp. 1497-1503, 2001.

[34] S. Kalyankrishna and J. R. Grandis, "Epidermal growth factor receptor biology in head and neck cancer," Journal of Clinical Oncology, vol. 24, no. 17, pp. 2666-2672, 2006.

[35] J. H. Ludes-Meyers, M. A. Subler, C. V. Shivakumar et al., "Transcriptional activation of the human epidermal growth factor receptor promoter by human p53," Molecular and Cellular Biology, vol. 16, no. 11, pp. 6009-6019, 1996.

[36] Y. Hiraishi, T. Wada, K. Nakatani et al., "EGFR inhibitor enhances cisplatin sensitivity of oral squamous cell carcinoma cell lines," Pathology and Oncology Research, vol. 14, no. 1, pp. 39-43, 2008. 


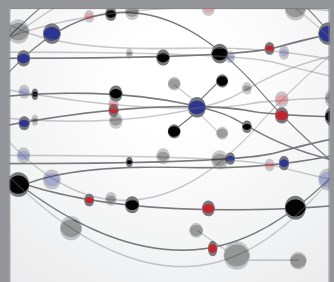

The Scientific World Journal
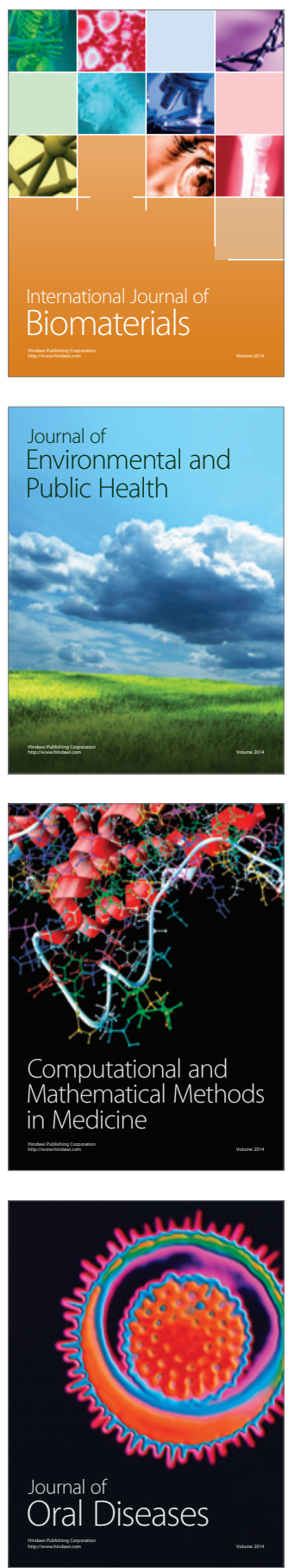
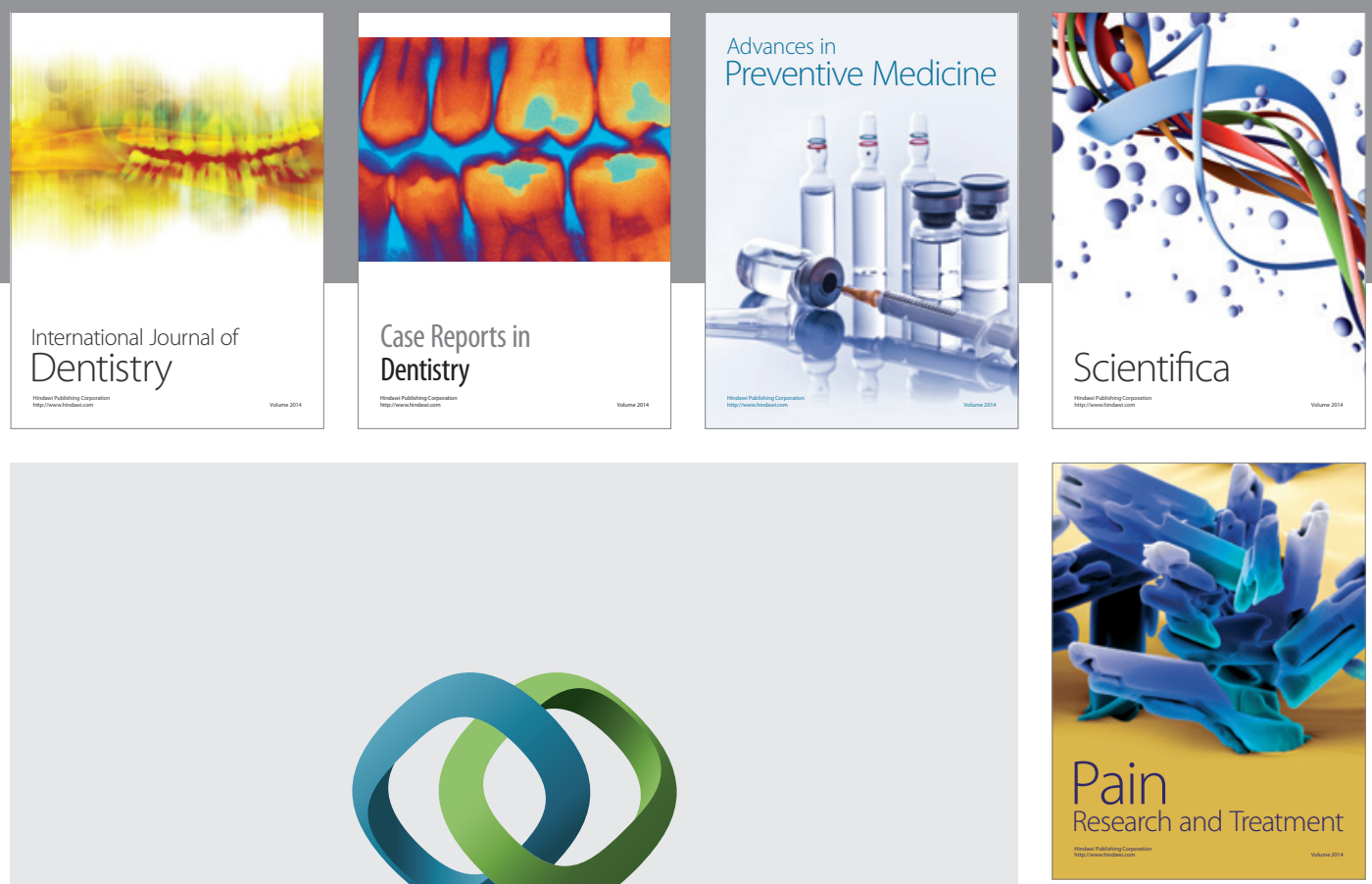

\section{Hindawi}

Submit your manuscripts at

http://www.hindawi.com
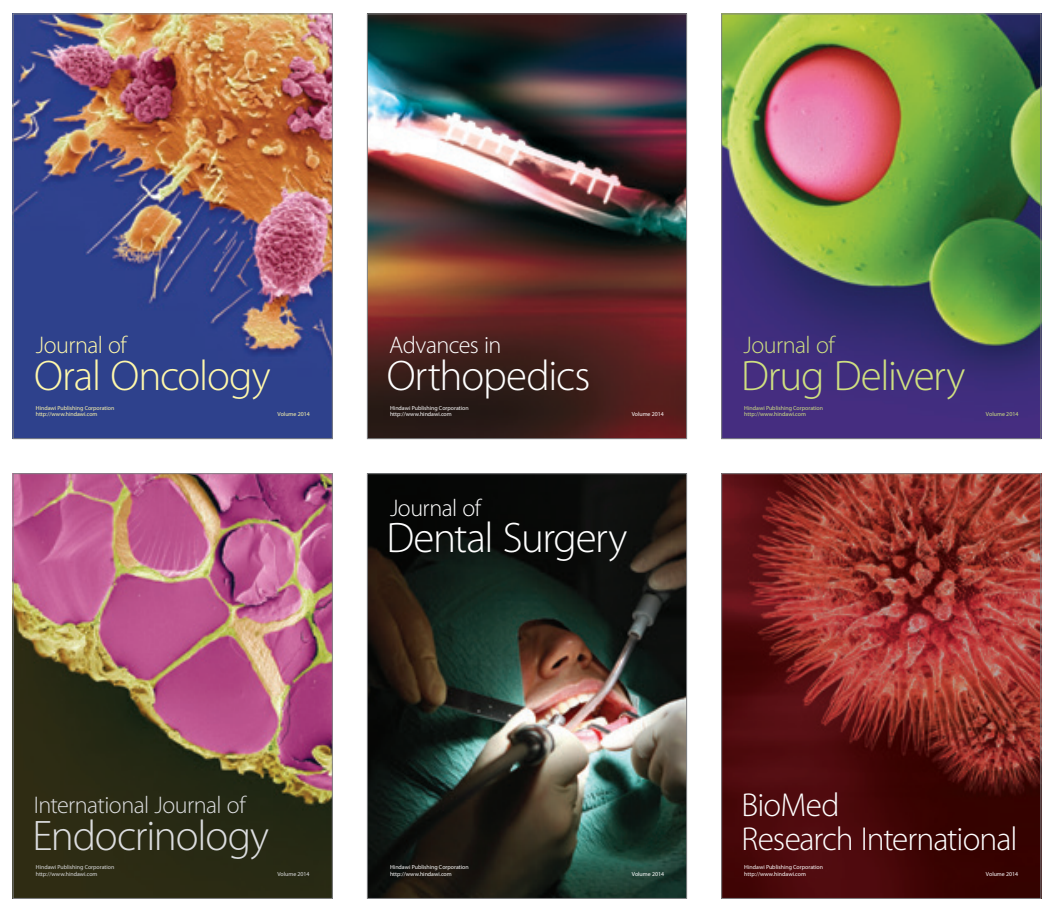

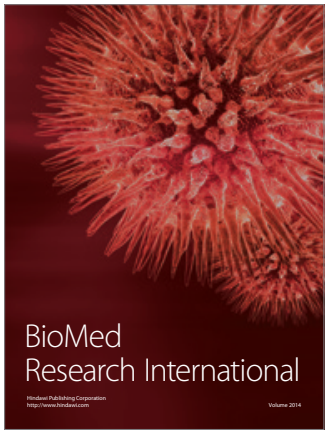

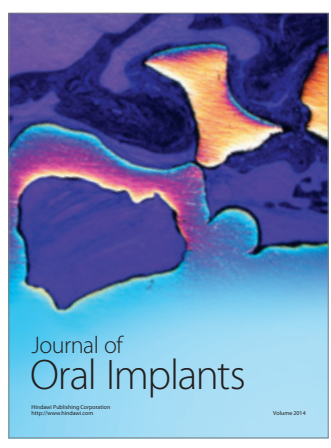
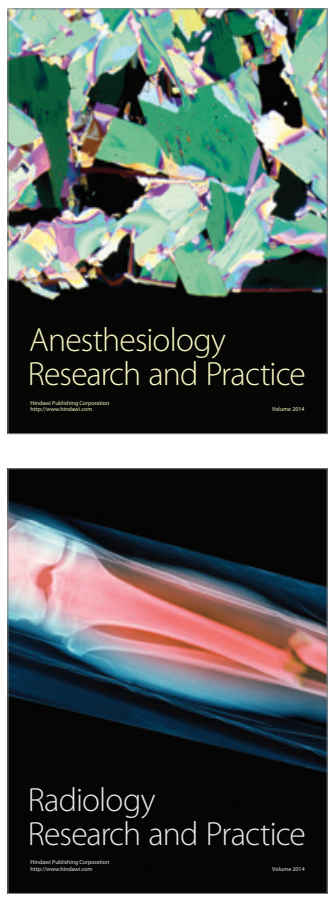